\title{
Analysis and simulation of the architecture of a growing root system: application to a comparative study of several tree seedlings
}

\author{
M. Colin-Belgrand ${ }^{1}$, L. Pages ${ }^{2}$, E. Dreyer ${ }^{1}$ and H. Joannes ${ }^{1}$ \\ 1 INRA, Centre de Recherches Forestières, BP 35, 54280 Seichamps, and \\ 2 INRA, Station d'Agronomie, Domaine-de-St-Paul, 84140 Montfavet, France.
}

\section{Introduction}

It has frequently been suggested that the shape and the spatial extension of root systems markedly influence the rate and patterns of nutrient uptake from the soil.

Many nutrient and water uptake models have been proposed, based on root distribution patterns; for instance, spatial (mostly vertical) distribution of roots may be related to physical and chemical properties of successive soil layers as in the empirical model of Gerwitz and Pages (1973). Parameters describing extension, such as total root length, explored soil volume and rooting density, are frequently used.

On the other hand, a root system may also be described as a network of resistances to nutrient and water transfers. It appears therefore important not only to quantify root distribution, but also to analyze the spatial ramified architecture, in other words, the connecting links between the different parts of the root system.

\section{Modeling root architecture}

The basis of rcot architecture modeling is an adequate definition of branching terminology. In this respect, two main approaches may be outlined. The first one is based on a topological or morphometric description of ramifications. Fitter (1987) applied this approach to describe and simulate root systems of various herbaceous species. Basic structural units are the links, straight segments between successive nodes (branching points). The order of these links is counted from the periphery of the branching structure towards the primary axis (hypocotyl). Main parameters are either topological (like magnitude) or geometric (like link lengths, branch spacing, branching angles). The main limitation of this approach is that it is purely descriptive and cannot be used to describe growth.

The second approach is based on developmental analysis beginning from the root origin and evolving with growth and 
increasing complexity. First-order roots originate from the hypocotyl and bear second-order laterals and so on (Hackett and Rose, 1972). In this way, each root member has a distinctive identity and each order of roots has specific dimensions, properties and branching patterns (Rose, 1983). In a developmental model, the simulation of root growth and ramification is based for each root-order on time of emergence of the successive axis, elongation rate and rate of lateral branching (Lungley, 1973; Rose, 1983).

More recently, new developmental models were proposed in which the movement of root tips through the soil is described (Pages and Aries, 1988; Diggle, 1988). These models differ from the previous ones because they all have root tips growing during each time step rather than having each tip growing individually for the entire duration.

We have recently developed a new method which allows a detailed analysis of a growing root system with all its dynamic aspects (Belgrand et al., 1987). It is also a developmental approach: a root is defined as the non-branched structure formed through the activity of a single apical meristem. The growth and architecture of growing root systems of young tree seedlings are studied by direct and non-destructive observations in 'minirhizotrons', where root growth occurs at the interface between the lower wall of rhizotrons and the soil.

The data acquisition system, presented in greater detail in this volume, is rootsegment based. In our method, synthetic parameters of root growth and architecture are specified in terms of growing time for each order (number of axis, time of emergence, elongation rate, branching characteristics, such as interbranch distance and length of the apical non-branching zone, defined by the region from the most visible apical $n+1$ order laterals to the axis tip). Statistical studies of these

Table I. Root architectural characteristics of 3 mo old seedlings.

\begin{tabular}{|c|c|c|c|c|}
\hline & Q. rubra & Q. petraea & A. holosericea & A. albida \\
\hline \multicolumn{5}{|l|}{ Taproot } \\
\hline $\begin{array}{l}\text { elongation rate }(\mathrm{cm} / \mathrm{day}) \\
(\mathrm{SD}) \\
\text { apical non-branching }\end{array}$ & $\begin{array}{l}1.5 \\
(0.15)\end{array}$ & $\begin{array}{l}1.6 \\
(0.23)\end{array}$ & $\begin{array}{l}1.2 \\
(0.14)\end{array}$ & $\begin{array}{c}1.9 \\
(0.30)\end{array}$ \\
\hline $\begin{array}{l}\text { length: average }(\mathrm{cm}) \\
\text { (SD) }\end{array}$ & $\begin{array}{l}7.3 \\
(3.20)\end{array}$ & $\begin{array}{l}7.6 \\
(2.13)\end{array}$ & $\begin{array}{l}7.3 \\
(3.40)\end{array}$ & $\begin{array}{l}10.6 \\
(3.72)\end{array}$ \\
\hline $\begin{array}{l}\text { interbranch distance } \\
\text { average }(\mathrm{cm}) \\
\text { (SD) }\end{array}$ & $\begin{array}{c}0.44 \\
(0.36)\end{array}$ & $\begin{array}{c}0.50 \\
(0.50)\end{array}$ & $\begin{array}{c}0.80 \\
(0.70)\end{array}$ & $\begin{array}{c}0.70 \\
(0.60)\end{array}$ \\
\hline \multicolumn{5}{|l|}{$\begin{array}{l}\text { Short lateral roots } \\
\text { final lenath }\end{array}$} \\
\hline $\begin{array}{l}\text { average }(\mathrm{cm}) \\
(\mathrm{SD})\end{array}$ & $\begin{array}{c}1.75 \\
(1.56)\end{array}$ & $\begin{array}{c}1.85 \\
(1.26)\end{array}$ & $\begin{array}{c}1.70 \\
(0.95)\end{array}$ & - \\
\hline \multicolumn{5}{|l|}{ Long lateral roots } \\
\hline $\begin{array}{l}\text { average } \\
\text { (SD) } \\
\text { final length }\end{array}$ & $\begin{array}{c}5.7 \\
(3.4)\end{array}$ & $\begin{array}{c}5.5 \\
(1.7)\end{array}$ & 0 & 3 \\
\hline $\begin{array}{l}\text { average }(\mathrm{cm}) \\
\text { (SD) }\end{array}$ & $\begin{array}{l}26.3 \\
(4.2)\end{array}$ & $\begin{array}{l}36.7 \\
(7.1)\end{array}$ & 0 & $\begin{array}{l}32.0 \\
(5.1)\end{array}$ \\
\hline
\end{tabular}


data allow the determination of elongation laws and branching patterns. They may then be integrated into a deterministic three-dimensional model (Pages and Aries, 1988).

This method has been applied to the analysis of root growth in several different tree species seedlings in order to explore the different architectural models. Two groups of species were used, oaks and several acacias, which show marked differences in shoot growth and ramification.

\section{Materials and Methods}

Acorns of oaks (Quercus petraea Liebl., $Q$. rubra du Roi) and seeds of acacias (Acacia albida Del., $A$. holosericea) were germinated on the same substrate (a homogeneous mixture of sandy clay and peat) in minirhizotrons with 4 replicate plants per species. The seedlings were grown under controlled climate in a growth cabinet $\left(150 \mu \mathrm{mol}\right.$ of PAR $\cdot \mathrm{m}^{-2} \cdot \mathrm{s}^{-1}, 22 / 16^{\circ} \mathrm{C}$ day/night temperature regime, $16 \mathrm{~h}$ daily photoperiod). Root growth was monitored every second day for 2 mo (Belgrand et al., 1987). Mean values of root characteristics are given in Table I.

\section{Results}

The forms of the root systems, as they appeared 2 mo after germination are drawn in Fig. 1. Root configuration is very similar for all presented species: a fast growing and orthogeotropic taproot bearing short second-order roots with plagiogeotropic and restricted growth; their final lengths never exceeded $10 \mathrm{~cm}$.

Taproot elongation is always linear and non-rhythmic, with a daily rate of about $1.4-1.9 \mathrm{~cm} / \mathrm{d}$ for oaks, $1.2 \mathrm{~cm} / \mathrm{d}$ for $A$. holosericea and $1.5-2.2 \mathrm{~cm} / \mathrm{d}$ for $A$. albida (Table 1).
Taproot branching patterns may be described through the interbranch distance distribution and the length of the apical non-branching zone (LAnbr). The interbranch distance is rather similar for the 2 oak species $(0.4-0.5 \mathrm{~cm})$ and for the 2 acacias $(0.6-10.9 \mathrm{~cm})$. No systematic changes in branch spacing were determined with time; the differentiation of lateral roots occurs in a strictly acropetal order (Fig. 2a) and is also regular along the taproot length. The LAnbr is also rather constant; it seems there was no trend of evolution of the LAnbr with either time or taproot length (Fig. 2b). Yet, there are specific differences, especially for $A$. albida (Table I).

Long lateral roots appear 3 mo after germination when the taproot reaches the bottom of the minirhizotron. Specific differences can be observed between oaks and acacias (Table I).

\section{Discussion and Conclusion}

At the seedling stage, we did not observe strong differences between growth models of the observed root systems. It should be noted that the values of the different architectural parameters, like branch spacing, are quite constant for seedlings, although the taproot elongation rate is very different. All shown species may be described as having a fast growing and regularly ramifying taproot, bearing more or less plagiogeotropic laterals with very restricted growth.

At this stage, we cannot differentiate distinct architectural models, but the number of long lateral roots could contribute to the expression of architectural models on older plants. There are 2 phases in the architecture setting: the first one, with taproot setting and an acropetal initiation and a limited development of lateral roots; 
$291 s$
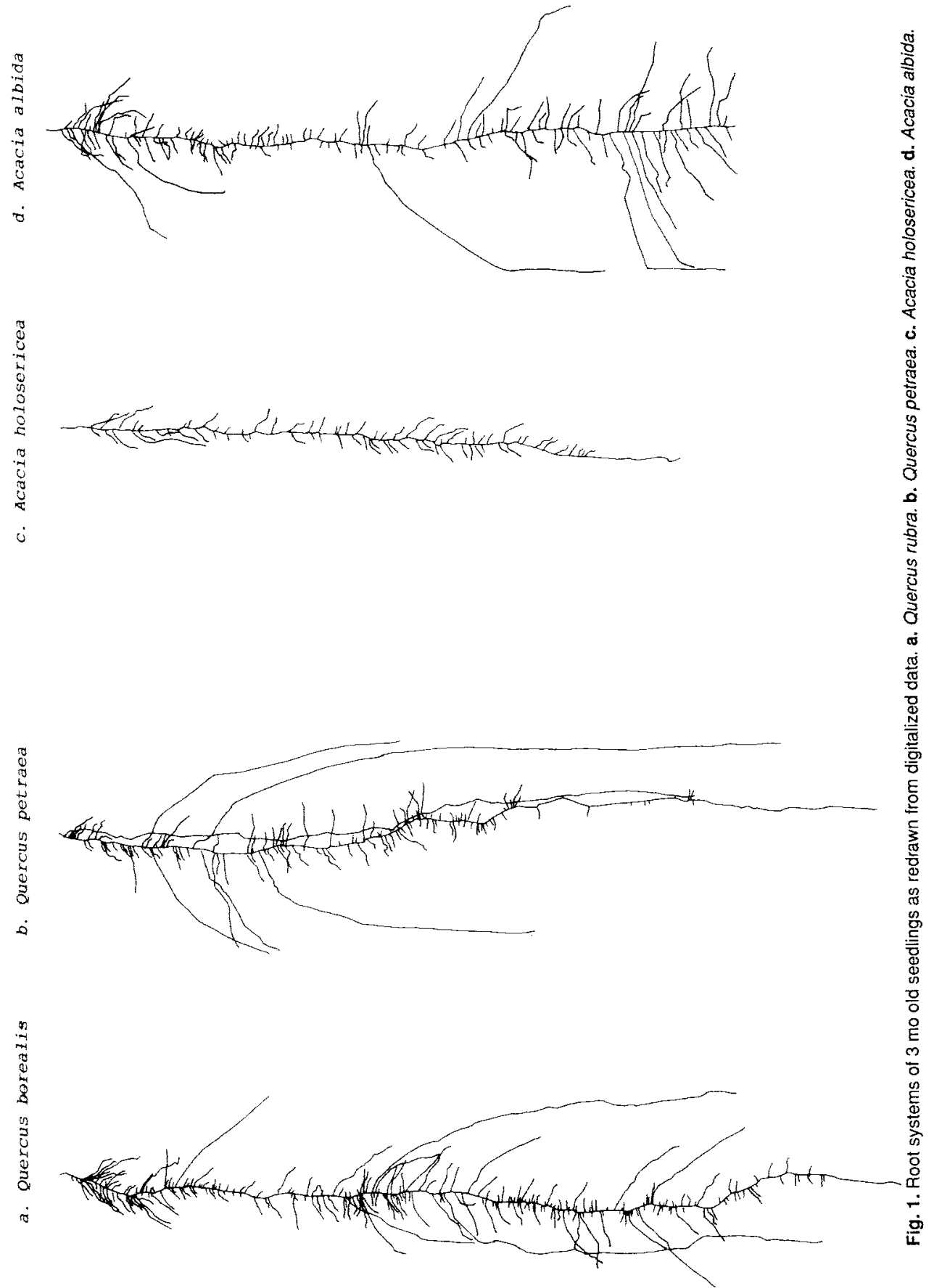
a

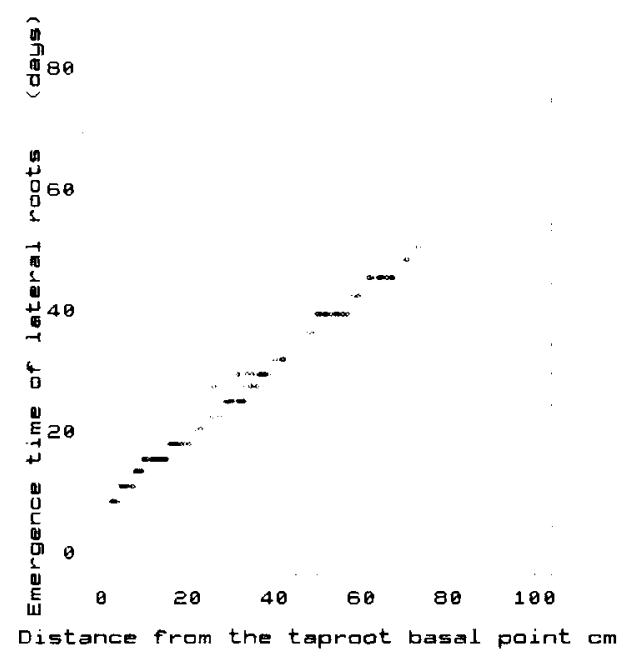

b

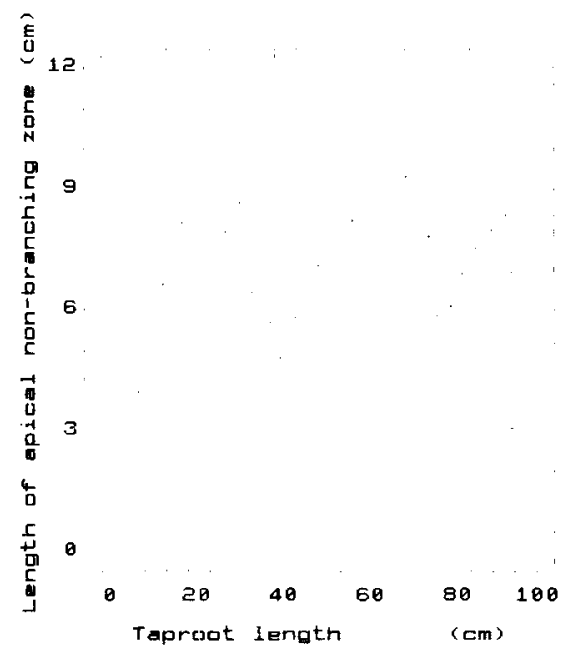

Fig. 2. Lateral root initiation of a 3 mo old red oak seedling. a. Evolution of initiation of lateral roots with time. b. Variability in length of the apical non-branching zone along the taproot length.

the second one with a strong plagiotropic root differentiation in non-acropetal order (Kahn, 1977). Our results concerning the development of long lateral roots could lean in the same way.

On the other hand, the influence of soil properties may be overriding on the changes of root architecture. The influence of physical soil properties is well known: for instance, number of lateral roots and rate of extension are greatly increased by mutilation of the taproot tip (Hackett, 1971). In the same way, effects of water stress on lateral root initiation and elongation have been reported (Jupp and Newman, 1987). An analogous effect of waterlogging can be observed (Riedacker and Belgrand, 1983). However, in these examples, there are no details in terms of root architecture. Our new method could be used for this kind of analysis.

\section{References}

Belgrand M., Dreyer E., Joannes H., Velter C. \& Scuiller I. (1987') A semi-automated data processing system for root growth analysis: appication to a growing oak seedling. Tree Physiol. 3, 393-404

Diggle A.J. (1988) ROOTMAP - a model in three-dimensional coordinates of the growth and structure of fibrous root systems. Plant Soil 105, 169-178

Fitter A.H. (1987) An architectural approach to the comparative ecology of plant root systems. New Phytol. 106 (suppl.), 61-77

Gerwitz A. \& Page R. (1973) An empirical mathematical model to describe plant root systems. J. Appl. Ecol. 11, 773-781

Hackett C. (1971) Relations between the dimensions of the barley root system: effects of mutilating the root axes. Aust. J. Biol. Sci. 24, 1057-1064

Hackett C. \& Rose D.A. (1972) A model of the extension and branching of a seminal root of 
barley, and its use in studying relations between root dimensions. II. Results and inferences from manipulation of the model. Aust. J. Biol. Sci. 25, 669-679

Jupp A.P. \& Newman E.I. (1987) Morphological and anatomical effects of severe drought on the roots of Lolium perenne L. New Phytol. 105, 393-402

Kahn F. (1977) Analyse structurale des systèmes racinaires des plantes ligneuses de la forêt tropicale dense humide. Candollea 32 , 321-358
Lungley D.R. (1973) The growth of root systems. A numerical computer simulation model. Plant Soil 38, 145-159

Pages L. \& Aries F. (1988) SARAH: modèle de simulation de la croissance, du développement et de l'architecture des systèmes racinaires. Agronomie 8, 888-897

Riedacker A. \& Belgrand M. (1983) Morphogénèse des systèmes racinaires des semis et boutures de chêne pédoncule. Plant Soil 71, 131-146 Rose D.A. (1983) The description of the growth of root systems. Plant Soil 75, 405-415 